\title{
Decentralized And Simultaneous Generation and Transmission Expansion Planning Through Cooperative Game Theory
}

\author{
Nanang Hariyanto, Muhammad Nurdin, Yanuarsyah Haroen, and Carmadi Machbub \\ Institut Teknologi Bandung, Bandung, Indonesia
}

\begin{abstract}
In the new paradigm, electric power system development should provide a negotiation space mechanism between all players with the objective function to maximize payoff distributed to each player in the system. Uncertainty risk and operate effectively and efficiently become a high consideration for all players in the decision making processes to select an investment and power system operation. This paper deals with simultaneous and desentralized with multiple objectives scenario within a global framework. The planning mechanism is prepared on the basis of cooperative game theory. Its coperative framework will encouraged an independently, distributed decision making in the competitive structure environtment. Main contributions of this paper are: a general model for power system planning in the form of cooperative game theory, and its time and spatial decomposition. This method will be implemented in Garver test system.
\end{abstract}

Index Terms: power system planning, game theory, Shapley bilateral, coalition formation, static security

\section{Introduction}

Decentralized policy of natural resources management, existing disparity of electric demand in sector classification and in regional level, also the needs for unbundling vertically integrated electric power business stimulate and modify significantly the process and mechanism in power system planning and development. Traditionally, electric power system planning was conducted as a centralized planning with the objective function to minimize investment and operation cost in a framework of welfare maximization for an established reliability services. In line with the restructuring of power industry, some research works have appeared on power system planning on the basis of competitive structure. Due to the the complexity of the problem itself, and some ambiguities in the policies regarding relationship between long-term planning horizon and day by day operations of deregulated power system, the models developed so far are not yet able to compatible to the needs of planners and policymakers.

In the new paradigm, electric power system development should provide a negotiation space mechanism between all players with the objective function to maximize payoff distributed to each player in the system. Uncertainty risk and operate effectively and efficiently become a high consideration for all players, including independent power producers, transmission owners, independent system operators and consumers in the decision making to select an investment and power system operation. Consequently, power system planning deals with a decentralized planning with multiple objectives scenario within a global framework, and its planning mechanism should be able to evolve adaptively on a number of planning horizons.

There have been a few research works on simultaneous generation and transmission expansion planning. Initial work conducted by incorporating the costs of generation and transmission facilities in a single objective formulation, that minimize total investment cost. A transportation models has been used to represent transmission existing network and its candidate expansion planning.

Received: November 28, 2009. Accepted: Desember 4, 2009 
Solution approach has been based on combination of Benders decomposition, maximum flow algorithms and linear programming used to power flow network [1,2].

Some research works in this field appear significantly, especially in application of game theory and reinforced learning. Vishnu Nanduri et all [11] propose a generation expansion planning using two-tier game theory with transmission network constraint in multi years planning. It also apply reinforced learning to solve matrix game of generation and transmission network development. Jianhui Wang [12] works also using a combination of coevolutionary computation with 2-level optimization for generation expansion planning. In other side Lina $\mathrm{P}$ Garces proposes a bilevel programming for transmission network expansion within uncertainties of power system market [7]. M Sadegh et all [8] works on simultaneous generation and transmission expansion conducted in a centralized planning using mixed integer non linear programming that includes variation of fuel cost based on type and locational geography. Jae Hyung Roh and M Shahidehpour propose a model for power system planning coordination of energy market and its transmission with a capacity cost of generation and transmission facilities [13]. Capacity payment is designed to enhance market investment, and also able to reflect locational value for addition of resources. This interaction is provided as iteratif mechanism within GenCo, TransCo and ISO and simulate it using Monte Carlo.

This paper deals with a concept and mechanism of planning processes in which is able to accommodate negotiation process and to compose a strategy of all players, hence a ParetoOptimal outcome solution will be achieved in electric power system. The planning mechanism is prepared on the basis of cooperative game theory. Its coperative framework will encouraged an independently, distributed decision making in the competitive structure environtment.

\section{Problem Formulation}

In the competitive structure, such as in Figure 1, regarding the increasing load demand in each area A, B and C, there are some choice independently in power system planning as a respons to meet the electric demand, that include : (i) running an expansion planning in each region to solve each problems, (ii) enhancement a tie line and import energy from another area, (iii) built a new plan and enhancement a tie line and sold its excess energy to another area.

Concerning the problems, a new approach is prepared to solve this problem using cooperative game mechanism. It provides a capability to propose an oportunity for all players to negotiate and stimulate interaction between them to make a coalition formation on the basis of individual competitive preferences.

For the system above, the players interact in the system include NewLoad, GenCo, TransCo as an owner of transmission network in each ara and tie line. It is assumed that all players are rational, and are always willing to maximize its profit in the planning.

In the simultaneous expansion generation and transmission planning, all players commited to (i) meet the load requirement within static security and economic constraints; (ii) all of cost for expansion planning will be provided together and all of benefit form that will be distributed based on marginal effort conducted by each player; (iii) shapley value mechanism will be used to allocated its benefit.

\section{A. Basic Formulation}

Consider a general N-persons cooperative game in which a player- $i$ will maximize/minimize its objective function :

$$
\begin{aligned}
& \int_{t_{0}}^{T} g^{i}\left[s, x(s), u_{1}(s), u_{2}(s), \ldots, u_{n}(s)\right] d s+q^{i}(x(T)), \\
& \text { for } i \in N=\{1,2, \ldots, n\}
\end{aligned}
$$

With the state dynamics in the form : 


$$
\begin{aligned}
& \dot{x}(s)=f\left[s, x(s), u_{1}(s), u_{2}(s), u_{3}(s) \ldots \ldots, u_{n}(s)\right], \\
& x\left(t_{0}\right)=x_{0}
\end{aligned}
$$

$x(s) \in X$ states as variable state of the game, and $\mathbf{m} V^{i}$ apply as a control part of player-i, for each $i \in N$.

In this case the players agree to cooperate and allocate cooperative payoff to fulfil the optimality principle of cooperative scheme. The solution of optimality principle will run along the cooperative state trajectory path $\left\{x_{s}^{*}\right\}_{s=t_{0}}^{T}$, that will be found rationally each player such a number of strategic sets to obtain Pareto optimal solution, and each allocation should meet a individual rationality.

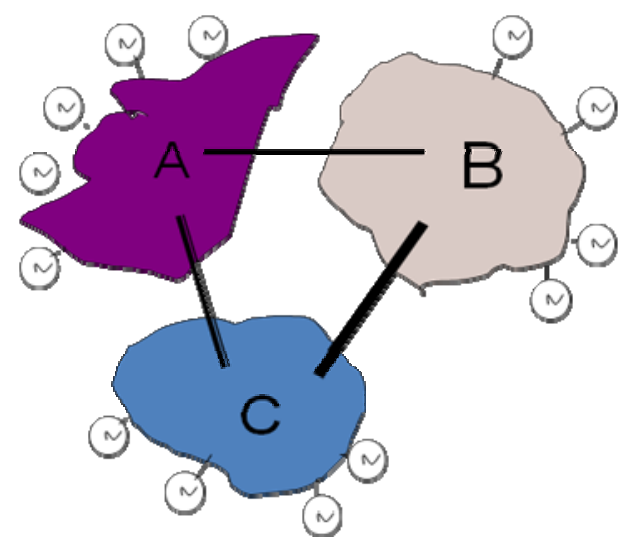

Figure. 1. Interarea electricity structure connedted by tie line, each area has an different generation, transmission and load

To fulfil group rationality of cooperative mechanism, the players have to maximize the sum of their payoffs subject to state dynamics equation above:

$\sum_{j=1}^{N}\left\{\int_{t_{0}}^{T} g^{j}\left[s, x(s), u_{1}(s), u_{2}(s), u_{3}(s), \ldots . ., u_{n}(s)\right] d s+q^{j}(x(T))\right\}$

With Pontryagins Maximum Principle, there are sets of optimal control $u^{*}(s)=\left[u^{*}(s), u^{*}(s)\right.$, $\mathrm{u}^{*}(\mathrm{~s}), \mathrm{u}^{*}(\mathrm{~s}) \ldots . .$. ... Subsituting this set of optimal control into (3) yields the optimal trajectory $\left\{x_{s}^{*}\right\}_{s=t_{0}}^{T}$, where

$$
\begin{aligned}
& x^{*}(t)=x_{0}+\int_{t_{0}}^{t} f\left[s, x(s) u^{*}(s)\right] d s, \\
& \text { for } t \in\left[t_{0}, T\right]
\end{aligned}
$$

The objective function for optimal trajectory condition is :

$\sum_{j=1}^{n}\left\{\int_{t_{0}}^{T} g^{j}\left[s, x^{*}(s), u^{*}(s)\right] d s+q^{j}\left(x^{*}(T)\right)\right\}$

where $v\left(N ; x_{0}, T-t_{0}\right)$. 


\section{B. Cooperative Game Theory}

The term of characteristic function was noted by $v$. The characteristic function is defined as: for every subset $\mathrm{S}$ from $\mathrm{N}$, the characteristic function $v$ of a game gives the biggest value $v(S)$ obtained by the members of $S$ if they work together and form a coalition, without any assistance from the other players outside $S$.

The boundary of this definition is the game value toward empty coalition is zero so that $v$ $(\varnothing)=0$. Shapley value is a measure of average contribution given by one player to the game. This value is related to the marginal value in economic study. For example, a coalitional game with definite player set $N=\{1,2,3 \ldots n\}$ with the characteristic function $v$ of $2^{N}$ possible coalition set. $N$ is the number of player in $S$ coalition. $v(S)$ represents the total payoff that can be obtained by $\mathrm{S}$ coalition with player i involved in coalition and $v(\mathrm{~S}-\{\mathrm{i}\})$ is payoff obtained without the player $i$. Shapley value is represented by $\varphi$ operator. $\varphi_{i}$ is the payoff of player $i$ in the game. The marginal contribution of player i is $v(S)-v(S-\{i\})$. The formula of Shapley value is:

$$
\begin{aligned}
\Phi^{v}\left(x_{0}, T-t_{0}\right) & =\left\{\Phi_{i}^{v}\left(x_{0}, T-t_{0}\right), i=1, \ldots, n\right\} \\
\Phi_{i}^{v}\left(x_{0}, T-t_{0}\right) & = \\
\sum_{S \subset N, i \subset S} \frac{(n-1) !(s-1) !}{n !}\left[v\left(S ; x_{0}, T-t_{0}\right)-v\left(S \backslash i ; x_{0}, T-t_{0}\right)\right] ; & \quad i=1, \ldots, n
\end{aligned}
$$

To avoid the combination complexity in Shapley value calculation, Ketchpel introduced Bilateral Shapley Value (BSV). This BSV approach has been used for decentralization and bilateral negotiation process among rational players.

If $C \subseteq P(A)$ is a coalition structure from set of agent $\mathrm{A}=\left\{a_{1}, \ldots, a_{m}\right\}$, where $C=C_{i} \cup C_{j} \subseteq A$ and $C_{i} \cap C_{j}=\varnothing$. Then $C$ is a coalition (bilateral) of disjoint coalition (n-agents) $C_{i}$ and $C_{j}(n \geq$ 0 . The Bilateral Shapley Value for coalition $C_{i}$ in bilateral coalition $C$ is defined as:

$$
\Phi_{C}\left(c_{i}\right)=\frac{1}{2} v\left(c_{i}\right)+\frac{1}{2}\left\{v(c)-v\left(c_{j}\right)\right\}
$$

$C_{i}$ and $C_{j}$ coalition are called as the composer of coalition $C, C_{i}$ as well as $C_{j}$ will form coalition $C$ if:

$$
v\left(C_{i}\right) \leq \varphi_{C}\left(C_{i}\right) \text { and } v\left(C_{j}\right) \leq \phi_{C}\left(C_{j}\right)
$$

\section{Propose Model For Development Planning}

\section{A. Improving Load Point Reliability Index}

A Garver test system as Figure 2 will be used as a model to show the application of cooperative game for power system planning. It has 2 generating plants 1 x150 MW and 1x 120 MW, 5 bus and 6 lines, with total load is about 190 MW.

Based on the existing condition, load at each bus is peak load, with load fator about 1 . The composite reliability at each load is represented as value of EENS (Expected Energy Not Served). Total EENS at Garver system is about 16,46 GWh per year, and is distributed for each bus as load point index per year, with a composition as : EENS at bus-1, bus-2, bus-3, bus-4 and bus-5 are about 0,28 GWh, 1,9 GWh, $0 \mathrm{GWh}, 10,7 \mathrm{GWh}$, and 1,14 GWh respectively. 
Improving of Garver model will be conducted using a heuristic planning to obtain a better reliability with load point index as EENS $=0$ at each bus, for normal and $\mathrm{N}-1$ contingency operation.

There are some alternative solutions to improve Garver system, include : (i) increase reserve capacity at bus-3, (ii) enhancement transmission for each branches; and do for (i) and (ii) simultaneously. Algorithm for choice the configuration alternatives shown as following below:

Algorithm 1

Step 1 : (Initialitation) data of existing generation and transmission and load.

Step 2 : Calculate EENS existing system based on composite reliability at load point

Step 3 : (Loop 1) If EENS $=0$, then finish and run to step 7

3.1 Add capacity of generation at certain bus

3.2 Running optimal ower flow

3.2.1 (Loop 2) If feasible optimal power flow, then finish to step 3

(i) Add line branch $i$

(ii) Running optimal power flow

3.2.2 (Loop 3) If feasible optimal power flow, then finish to step 3

(i) Running load shedding at certain bus

(ii) Running optimal power flow

(iii) Back to step 3.2.2 loop 3

Step 4 : Running $N-1$ contingency analysis

Step 5 :

Calculate EENS for configuration $k$-th; calculate annualized investment for $k$-th; calculate the ratio of delta EENS to annualized generation and tranmission investment.

Step 6 :

Sorting all configuration 1 -st to $k$-th based on ratio above, and choose the configuration

Step 7 : Finish and stop.

Planned configuration will be used on the basis of highest ratio of delta EENS to annualized investment needed. Based on algorithm-1, coalition between of existing network configuration with exteded generator $80 \mathrm{MW}$ at bus 3 will solve the requirement of reserve power for N-1 contingency, for example generator $150 \mathrm{MW}$ failed to supply the system.

Economic dispatch mechanism is based on optimal power flow analysis and if the result is not feasible ( over load in line from bus-2 to bus-3 and under voltage at bus-4), than load shedding mechanism at bus-4 will be done about 7 MW. EENS is calculated for each possible configuration.

Calculation result is shown in table 1 and based on this result configuration 8-th will selected in which coalition between (i) existing system Garver, (ii) new additional generation plant abot $80 \mathrm{MW}$, and (iii) enhancement of transmission line between bus-2 to bus-3, with ratio about $3.126 \mathrm{KWh} / \$$ investment per year. The configuration result is shown as figure 3 .

Investment cost of configuration 8-th becomes a characteristic function of existing system Garver 5 bus. It effects to payoff distributed if the existing system cooperate with another players. Payoff obtained by exsiting Garver will face as a decreasing of investment cost because some of investment is provided by another players, such as New GenCo or TransCo and New Load that will collaborate to the system. 


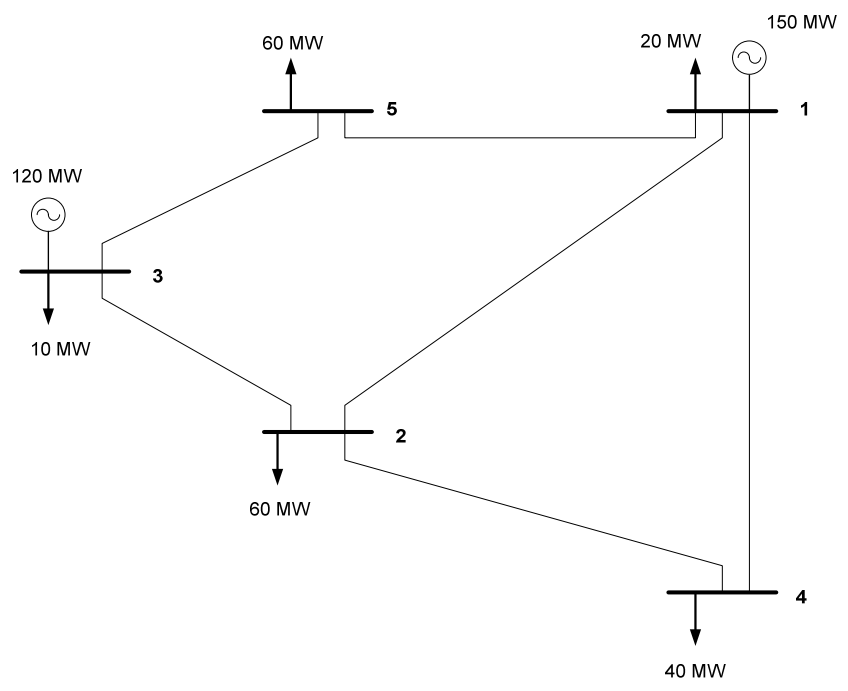

Figure. 2. The existing models of generation and transmission lines of Garver system.

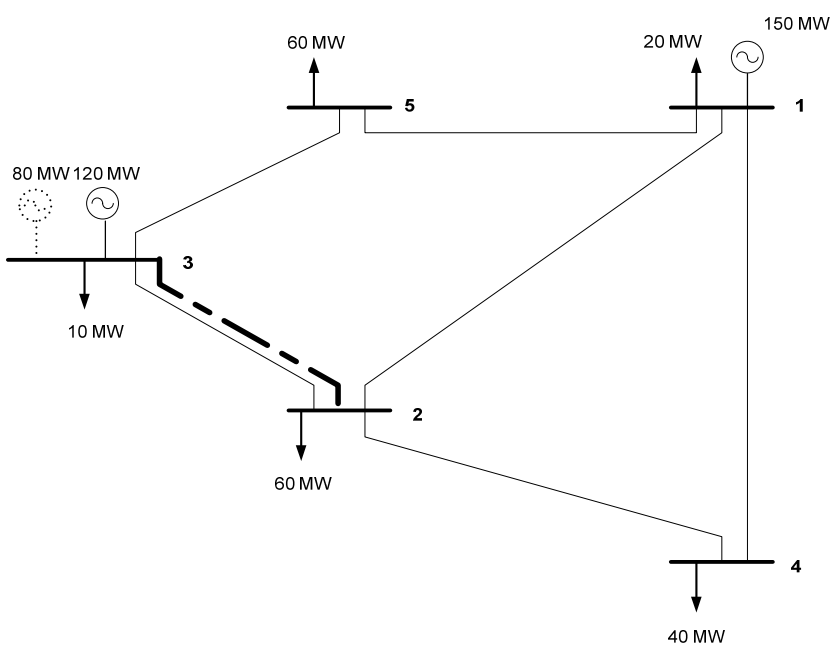

Figure 3 Configuration 8-th to improve reliability at load point, coalition between existing system Gaver, New Generating Plant $80 \mathrm{MW}$, and enhancement tranmission line from bus2 to bus 3 .

\section{Test Case}

As explained by cooperative game theory principle, players always try to maximize their profit. In this planning process, payoff acquired by creating a coalition is a reduced investment cost. This is because, by creating a coalition, player can create an agreement to divide payoff according to marginal effort of each player. In this condition, coalition will always happen if each player gets payoff at least the same as payoff acquired before coalition. Previous assessment of Garver system can be developed by taking into load expansion for every bus. Thus, there are eight players in the simultaneous planning process of generation system and transmission network: 


\section{Player I:}

Existing system, which includes 5 buses, 2 existing generator in bus 1 and bus 3, 6 transmissions that connect buses, and existing load.

\section{Player II:}

Generator Company, called GenCo, which will build a new generator in bus 3.

\section{Player III:}

Transmission Company, called TransCo, which will build transmission network for existing buses.

\section{Player IV, V, VI, VII, and VIII:}

Consumers that require electricity in bus 1 , bus 2 , bus 3 , bus 4 , and bus 5 . The requirement of the company is known previously.

\section{Planning Principle:}

The principles in this planning process should (i) meet the requirement for both existing and new loads (ii) satisfy the need of static security criterion and condition of ENNS $=0$ in N-1 contingency and by (iii) maximize payoff acquired by each player.

\section{A. Individual Characteristic Function}

The players will have their own characteristic function and will create coalition with other player, to achieve higher payoff. In this planning, all players have significant needs to existing system due its existing infrastructure. With the existence of load in bus 1 through bus 5, existing system will be subjected to declining rate of composite reliability in every bus and increasing EENS. Coalition between existing system and GenCo increase system reliability to fulfill load demand and to decrease EENS that occurs.

\section{B. Coalition Development}

Coalition between existing system and TransCo will also increase system reliability to meet load demand and to decrease EENS that occurs. Coalition between every player will increase system reliability to fulfill load demand, to decrease EENS and to increase payoff for every player.

This payoff is higher than payoff for fulfilling needs marginally. As such, every player will have significant needs to existing system because existing system has fundamental network configuration. This network configuration is a way for other players to give their benefit so that the players will have increased profit.

In the first case, GenCo will be able to supply power to load through transmission line in the existing network. For GenCo, utilizing existing network is more profitable than investing in building new transmission network to the load. Principally, GenCo may develop new transmission rather than using existing transmission line to load center if it is more profitable in the end. Coalition between GenCo and existing system will increase system's reliability because GenCo can increase reserved power to load center when contingency occurs, especially in case of generation outage from the system.

In conclusion, the coalition gives benefit to existing system, load, and GenCo according to marginal effort of every player. This will cause a coalition payoff distribution for the players. GenCo obtains profit in the form of revenue that is obtained from system revenue because system can reduce investment cost to improve system's reliability. Investment cost can be reduced because system does not need to build its own generator. Furthermore, operationally, GenCo will also obtain profit from electricity market. In line with rationality principle, GenCo should obtain higher payoff than its characteristic function. 
In the second case, TransCo cannot operate on its own transmission lines because there is no profit obtained in relation to increased reliability. On the other hand, if TransCo enters a coalition with existing system, TransCo will give benefit for system because system rreliability will be increased. The system reliability is increased because of new line developed by TransCo. TransCo can ensure power supply to load center both in normal operational condition and in contingency operational condition. Thus, security criterion is fulfilled by the system.

In conclusion, in relation to marginal effort of TransCo, TransCo will obtain its payoff share from reduced investment cost for developing new transmission line by existing system or existing coalition with GenCo. This is because TransCo provides the new transmission line. Operationally, TransCo will obtain rent fee of the line.

In the third case, the player is load. Coalition between this load and existing system or existing coalition with GenCo and TransCo will reduce investment that should be provided by the load. By entering a coalition with the system, the load will obtain profit because the load does not have to invest in building its own generator.

Table 1

Configuration Alternatives and Its Coalition for Improving Reliability

\begin{tabular}{|c|c|c|c|c|c|c|c|c|c|c|c|c|}
\hline \multirow[b]{2}{*}{$\begin{array}{c}\text { Confi } \\
\text { guration }\end{array}$} & \multicolumn{3}{|c|}{ Coalition } & \multicolumn{6}{|c|}{ EENS } & \multirow{2}{*}{$\begin{array}{l}\text { Invest. } \\
\text { (Mill. \$) }\end{array}$} & \multirow{2}{*}{$\begin{array}{l}\text { ENS Cost } \\
\text { (Mill.\$) }\end{array}$} & \multirow{2}{*}{$\begin{array}{c}\text { Ratio } \\
\text { (Kwh/\$) }\end{array}$} \\
\hline & Existing & $\begin{array}{c}\text { GenCo } \\
\text { at Bus } 3 \\
\text { (MW) }\end{array}$ & Line & $\begin{array}{l}\text { Bus-1 } \\
\text { (MWh) }\end{array}$ & $\begin{array}{l}\text { Bus-2 } \\
\text { (MWh) }\end{array}$ & $\begin{array}{l}\text { Bus-3 } \\
\text { (MWh) }\end{array}$ & $\begin{array}{l}\text { Bus-4 } \\
\text { (MWh) }\end{array}$ & $\begin{array}{l}\text { Bus-5 } \\
\text { (MWh) }\end{array}$ & $\begin{array}{l}\text { Total } \\
\text { (MWh) }\end{array}$ & & & \\
\hline Existing & Ok & - & - & $2.786,5$ & $1.899,9$ & - & $10.639,2$ & $1.139,9$ & $16.465,5$ & - & 1,140 & \\
\hline 2 & Ok & 80 & - & - & - & - & $1.123,0$ & - & $1.123,0$ & 4,835 & 1,123 & 2,575 \\
\hline 3 & $\mathrm{Ok}$ & - & Line 2-3 & $2.783,3$ & $1.897,7$ & - & 10627,1 & 1012,1 & $16.320,2$ & 0,115 & 16,320 & 0,009 \\
\hline 4 & Ok & - & Line 2-4 & $2.780,1$ & $1.895,5$ & - & $10.615,0$ & $1.137,3$ & $16.427,9$ & 0,231 & 16,428 & 0,002 \\
\hline 5 & Ok & - & Line 1-2 & $2.783,3$ & $1.897,7$ & - & $10.627,1$ & $1.012,1$ & $16.320,2$ & 0,115 & 16,320 & 0,009 \\
\hline 6 & Ok & - & Line 3-5 & $2.780,1$ & $1.769,2$ & - & $10.615,0$ & $1.137,3$ & $16.301,6$ & 0,230 & 16,302 & 0,010 \\
\hline 7 & Ok & - & Line 1-5 & $2.783,3$ & $1.771,2$ & - & $10.627,1$ & $1.138,6$ & $16.320,2$ & 0,115 & 16,320 & 0,009 \\
\hline 8 & Ok & 80 & Line 2-3 & - & - & - & - & - & - & 5,268 & - & 3,126 \\
\hline 9 & Ok & 80 & Line 2-4 & - & - & - & 746,9 & - & 746,9 & 5,264 & 0,747 & 2,615 \\
\hline 10 & Ok & 80 & Line 1-2 & - & - & - & $1.120,4$ & - & $1.120,4$ & 5,065 & 1,120 & 2,481 \\
\hline 11 & Ok & 80 & Line 1-4 & - & - & - & 497,4 & - & 497,4 & 5,565 & 0,497 & 2,634 \\
\hline 12 & Ok & 80 & Line 3-5 & - & - & - & - & - & - & 5,321 & - & 3,094 \\
\hline 13 & Ok & 80 & Line 1-5 & - & - & - & 747,8 & - & 747,8 & 5,165 & 0,748 & 2,658 \\
\hline
\end{tabular}


Table 2

Individual Characteristic Function of Each Player

\begin{tabular}{|c|c|c|c|c|c|}
\hline \multirow[t]{2}{*}{ Pemain } & \multicolumn{2}{|c|}{ Investment needed *) } & \multicolumn{2}{|c|}{ Investment (Mill. US\$) } & \multirow{2}{*}{$\begin{array}{c}\text { Characteristic } \\
\text { Function in Mill US\$ }\end{array}$} \\
\hline & $\begin{array}{c}\text { Power Plant at } \\
\text { Bus-3 }\end{array}$ & Line & Power Plant & Line & \\
\hline Exsisting & PLTU $80 \mathrm{MW}$ & Saluran 2-3 & 5,153 & 0,115 & $-5,268$ \\
\hline GenCo & - & - & - & - & - \\
\hline TransCo & - & - & - & - & - \\
\hline Load at Bus-1 $10 \mathrm{MW}$ & Diesel 2x $10 \mathrm{MW}$ & - & 0,795 & - & $-0,795$ \\
\hline Load at Bus-2 $40 \mathrm{MW}$ & Diesel 2x $40 \mathrm{MW}$ & - & 3,179 & - & $-3,179$ \\
\hline Load at Bus-3 $5 \mathrm{MW}$ & Diesel 2x 5 MW & - & 0,379 & - & $-0,379$ \\
\hline Load at Bus-4 $10 \mathrm{MW}$ & Diesel 2x 25 MW & - & 1,987 & - & $-1,987$ \\
\hline Load at Bus-5 $10 \mathrm{MW}$ & Diesel 2x 60 MW & - & 4,769 & - & $-4,769$ \\
\hline
\end{tabular}

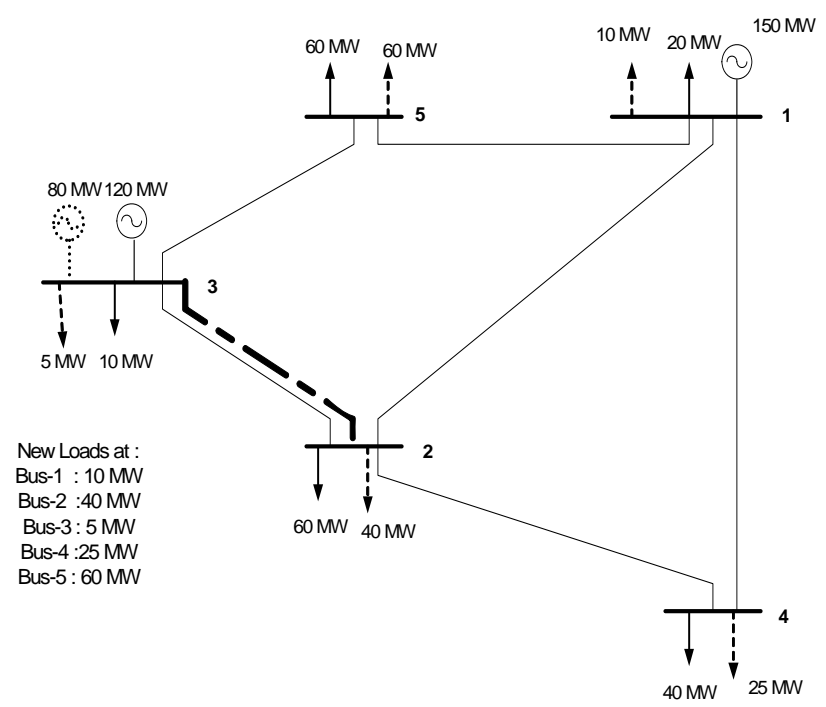

Figure 4 New configuration planned that consist of existing power system, New Generator 80 MW at bus-3, and enhancement new lines from bus-2 to bus-3, and estimated additional load at each bus. 
Table 3

Coalition Characteristic Function of Each Coalition

\begin{tabular}{|c|c|c|c|}
\hline Coalition & Players and Coalition & Coalition Investment & $\begin{array}{c}\text { Charactristic } \\
\text { Functions in } \\
\text { Mill. US\$ }\end{array}$ \\
\hline 1 & Eks & Gen 1 x 80 MW, 1 x line- 1 & $-5,269$ \\
\hline 2 & GenCo & No Investment needed in its coalition & 0 \\
\hline 3 & TransCo & No Investment needed in its coalition & 0 \\
\hline 4 & NL1 & Diesel Gen 2 × $10 \mathrm{MW}$ & $-0,795$ \\
\hline 5 & NL2 & Diesel Gen 2 x 40 MW & $-3,179$ \\
\hline 6 & NL3 & Diesel Gen 2 x 5 MW & $-0,379$ \\
\hline 7 & NL4 & Diesel Gen 2 x 25 MW & $-1,987$ \\
\hline 8 & NL5 & Diesel Gen 2 x 60 MW & $-4,769$ \\
\hline 9 & Eks-GenCo & $1 \mathrm{x}$ line- 1 & $-0,115$ \\
\hline 10 & Eks-TransCo & Gen 1 x 80 MW, 1 x line- 1 & $-5,153$ \\
\hline 11 & Eks-NL1 & Gen 1 x 90 MW, 1 x line-1 & $-6,001$ \\
\hline 12 & Eks-NL2 & Gen $1 \times 120$ MW, $1 \times$ line- 1 & $-8,116$ \\
\hline 13 & Eks-NL3 & Gen 1 x 85 MW, 1 x line-1 & $-5,605$ \\
\hline 14 & Eks-NL4 & Gen $1 \times 105$ MW, $1 \times$ line- $1,1 \times$ line- 2 & $-7,326$ \\
\hline 15 & Eks-NL5 & $\begin{array}{c}\text { Gen } 140 \text { MW, } 1 \text { x line- } 1 \text {, } \\
1 \text { x line- } 5\end{array}$ & $-9,482$ \\
\hline 16 & Eks-GenCo-TransCo & No Investment needed in its coalition & 0 \\
\hline 17 & Eks-GenCo-NL1 & $1 \mathrm{x}$ line-1 & $-0,115$ \\
\hline 18 & Eks-GenCo-NL2 & $1 \mathrm{x}$ line-1 & $-0,115$ \\
\hline 19 & Eks-GenCo-NL3 & $1 \mathrm{x}$ line- 1 & $-0,115$ \\
\hline 20 & Eks-GenCo-NL4 & $1 \mathrm{x}$ line-1, 1xline-2 & $-0,346$ \\
\hline 21 & Eks-GenCo-NL5 & $1 \mathrm{x}$ line-1, 1 xline-5 & $-0,231$ \\
\hline 22 & Eks-GenCo-TransCo-NL5 & No Investment needed in its coalition & 0 \\
\hline 23 & Eks-GenCo-NL1-NL5 & $1 \mathrm{x}$ line- $1,1 \mathrm{xline}-5$ & $-0,231$ \\
\hline 24 & Eks-GenCo-NL2-NL5 & $1 \mathrm{x}$ line-1, $1 \mathrm{xline}-5$ & $-0,231$ \\
\hline 25 & Eks-GenCo-NL3-NL5 & $1 \mathrm{x}$ line- $1,1 \mathrm{xline}-5$ & $-0,231$ \\
\hline 26 & Eks-GenCo-NL4-NL5 & $1 \mathrm{x}$ line-1, 1xline-5, $1 \mathrm{x}$ line- 2 & $-0,461$ \\
\hline 27 & $\begin{array}{l}\text { Eks-GenCo-TransCo-NL2- } \\
\text { NL5 }\end{array}$ & No Investment needed in its coalition & 0 \\
\hline 28 & Eks-GenCo-NL1-NL2-NL5 & $1 \mathrm{x}$ line-1, $1 \mathrm{xline}-5$ & $-0,231$ \\
\hline 29 & Eks-GenCo-NL2-NL3-NL5 & $1 \mathrm{x}$ line- $1,1 \mathrm{xline}-5$ & $-0,231$ \\
\hline 30 & Eks-GenCo-NL2-NL4-NL5 & $1 \mathrm{x}$ line-1, 1xline-5, $1 \mathrm{x}$ line- 2 & $-0,461$ \\
\hline 31 & $\begin{array}{c}\text { Eks-GenCo-NL2-NL4- } \\
\text { NL5-TransCo } \\
\end{array}$ & No Investment needed in its coalition & 0 \\
\hline 32 & $\begin{array}{l}\text { Eks-Genco-NL1,NL2-NL4- } \\
\text { NL5 }\end{array}$ & $1 \mathrm{x}$ line- 1 , 1 xline-5, 1 x line- 2 & $-0,461$ \\
\hline 33 & $\begin{array}{l}\text { Eks-Genco-NL1,NL2-NL3- } \\
\text { NL4-NL5 }\end{array}$ & $1 \mathrm{x}$ line- 1 , 1 xline-5, $1 \mathrm{x}$ line- 2 & $-0,461$ \\
\hline 34 & $\begin{array}{l}\text { Eks-Genco-NL1,NL2-NL3- } \\
\text { NL4-NL5-TransCo }\end{array}$ & Tak ada investasi di koalisi & 0 \\
\hline
\end{tabular}

Increasing load at each bus will decrease a reliability level, and it needs a network reconfiguration to obtain its reliability previously. For this case, to obtain EENS $=0$ at N-1 contingency, heuristically it needs an additional capacity at bus 3 to supply a reserve power, and expanding the existing network in all branches. 
Algorithm 2

Step 1 : (Initialitation)

(i) Existing data for generating plant, transmission network and existing load, an estimated incremental load for each bus per year,

(ii) Establish operation criteria include static security, meet demand and EENS=0 at N-I contingency.

Step 2 :

(i) Establish the first year of planning $k=1$

(ii) Establish heuristically alternatives of generating plant location and new transmission network

(iii) Calculate individual characteristic function of all players: Existing, GenCo, TransCo and New Load. The value of individual characteristic function are calculated on the basis of investment cost in power plant or transmission lines and ENS Cost.

\section{Step 3 :}

Arrange coalition between players $i$-th, $i=1$ to $N$. For this purpose, consider the requirements of coalition structure that includes power and energy balance, the connection between generating plant, transmission lines and load.

For each coalition i-th, running an optimal power flow

If optimal power flow is feasible, then construct a coalition i-th Add new line in brach i-th, Add generating capacity at certain bus

Running optimal power flow

Calculae also EENS of the coalition $i$-th

\section{Step 4 :}

Calculate the characteristic function of coalition i-th

Calculate Shapley Bilateral Value for its coalition

Choose the coalition $i$-th

\section{Step 5 :}

Calculate investment allocation for ecah player

Calculate payoff for each player

Compare payoff each players with individual investment of each player

Step 6 : Finish, set its configuration as planning result.

For this case, payoff obtained by GenCo is cost allocation from grand coalition, includes revenue from energy sold minus fuel cost and operation and maintenance cost. Payoff achieved by TransCo is cost allocation from grand coalition plus payment form rent cost of transmission line.

\section{Planning result}

Bilateral Shapley Value calculation is conducted to see the maximum payoff obtained by existing system regarding the coalition of 2 players, 3 players, 4 players, 5 players, 6 players, 7 players, and grand coalition that it consists of existing system and other players.

For example, BSV calculation is provided for coalition 11 in table 3, between existing system and New Load at bus-1 NL1. Characteristic function of coalition of 2 players (existing system and NL1) is about 6,001 Mill.US\$, in the form of investment planning for generating plant of $90 \mathrm{MW}$, and new installation of transmission lines from bus-2 to bus-3. 
Individual Characteristic function of existing system is about 5,269 Mill. US\$ in the form of investment needed to increase reliability level up to EENS $=0$ at $\mathrm{N}-1$ contingency condition. In other side, individual characteristic function of NL1 is about 0,795 Mill.US\$. Based on data explained above, it is able to calculate,

1. BSV for existing players $=0.5 \mathrm{x}-5.269+0.5 \times(-6.001-(-0.795))=-5.2375$ Mill. US\$

2. $\mathrm{BSV}$ for NL1 player $=0.5 \mathrm{x}-0.795+0.5 \times(-6.001-(-5.269))=-0.7635$ Mill. US\$

3. From this calculation, it can be shown that existing system obtains a benefit about 0.0315 Mill.US\$, that is a differences between the investment needed to increase reliability level to investment needed that should be paid to if it has a coalition with NL1.

4. Therefore, the player NL1 has a benefit about 0.0315 Mill.US\$, in which it is a differences between individual investment of NL1 to investment should be paid to system in its coalition.

On the basis of NSB calculation for 2 players coalition as in table 4, then existing system has a control authority, and is able to choose GenCo as a first coalition, due to maximize benefit obtained by existing player. This 2 players coalition generates a benefit of 2,577 Mill. US\$ for each player.

Table 4

Pay off Distribution for 2 Players Coalition

\begin{tabular}{|c|c|c|c|c|}
\hline Coalition & \multicolumn{2}{|c|}{ NSB } & \multicolumn{2}{|c|}{ Benefit } \\
\hline & Exist & GenCo & Exists & GenCo \\
\hline Existing -GenCo & $-2,692$ & 2,577 & 2,577 & 2,577 \\
\hline & Exist & TransCo & Exist & TransCo \\
\hline Existing -TransCo & $-5,211$ & 0,058 & 0,058 & 0,058 \\
\hline & Exist & NL1 & Exist & NL1 \\
\hline Existing -NL1 & $-5,2375$ & $-0,7635$ & 0,0315 & 0,0315 \\
\hline & Exist & NL2 & Exist & NL2 \\
\hline Existing-NL2 & $-5,103$ & $-3,013$ & 0,166 & 0,166 \\
\hline & Exist & NL3 & Exist & NL3 \\
\hline Existing-NL3 & $-5,2475$ & $-0,3575$ & 0,0215 & 0,0215 \\
\hline & Exist & NL4 & Exist & NL4 \\
\hline Existing-NL4 & $-5,304$ & $-2,022$ & $-0,035$ & $-0,035$ \\
\hline & Exist & NL5 & Exist & NL5 \\
\hline Existing-NL5 & $-4,991$ & $-4,491$ & 0,278 & 0,278 \\
\hline
\end{tabular}

Based on algorithm 2, it can be shown that the payoff distribution to each player for every coalition occurs as in table 5. 
Table 5

Pay off Distribution For Each Coalition Step

\begin{tabular}{|l|cccccccrr}
\hline & Eks & GenCo & TransCo & NL1 & NL2 & NL3 & NL4 & NL5 & Investment \\
In Mill,US\$ \\
\hline Coalition of 1 player & $-5,269$ & 0,000 & 0,000 & $-0,795$ & $-3,179$ & $-0,379$ & $-1,987$ & $-4,769$ & $-16,378$ \\
Coalition of 2 players & $-2,692$ & 2,577 & & & & & & & $-0,115$ \\
Coalition of 3 players & $-1,529$ & 3,740 & & & & & & $-2,443$ & $-0,231$ \\
Coalition of 4 players & $-1,131$ & 4,138 & & & $-1,590$ & & & $-1,648$ & $-0,231$ \\
Coalition of 5 players & $-1,022$ & 4,247 & & & $-1,150$ & & $-1,109$ & $-1,428$ & $-0,461$ \\
Coalition of 6 players & $-0,997$ & 4,272 & & $-0,398$ & $-1,051$ & & $-0,910$ & $-1,378$ & $-0,461$ \\
Coalition of 7 players & $-0,991$ & 4,278 & & $-0,303$ & $-1,027$ & $-0,190$ & $-0,862$ & $-1,367$ & $-0,461$ \\
Coalition of 8 players & $-0,987$ & 4,282 & 0,231 & $-0,245$ & $-1,013$ & $-0,074$ & $-0,834$ & $-1,359$ & 0,000 \\
\hline
\end{tabular}

The configuration result of each step coalition is shown as Figure 5

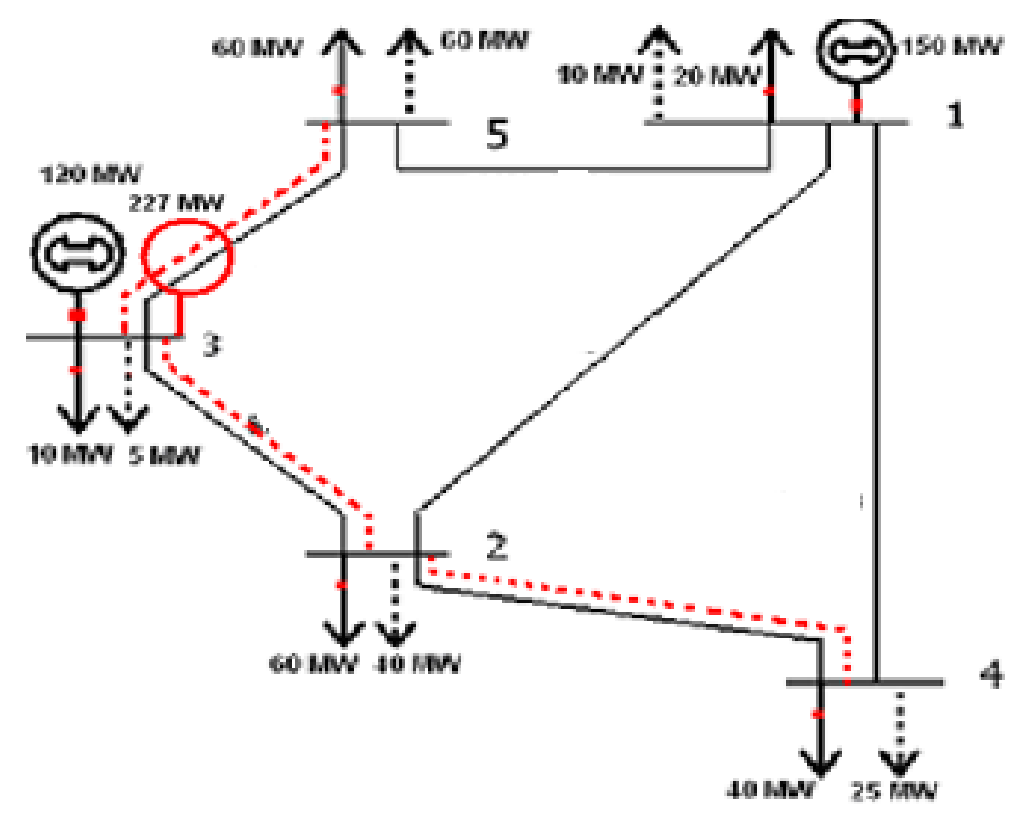

Figure 5 New configuration planned that consist of existing power system, New Generator 227 MW at bus-3, and enhancement new lines from bus-2 to bus- 3 , from bus- 2 to bus- 4 , and line from bus 3 to bus 5 .

\section{Conclusion}

Decentralized and simultaneous planning of electric power generation and transmission network that provides negotiation space for players in the process can be accomplished by using cooperative game theory. In this developed planning process, operational aspect, such as operational security criterion, is included in every process of coalition in its desired EENS value. In every process of coalition, players in the system can negotiate their commitment in determining characteristic function value. This characteristic function value is used to determine Shapley Bilateral value while also influencing the process of coalition between players. In conclusion, 
Nanang Hariyanto, et al.

(a) Coalition in every process of cooperative game provides negotiation option between each player and option for a player to enter the coalition earlier than the other players.

(b) Player that enters the coalition earlier will have higher payoff than others that enter the coalition later.

(c) In the case of simultaneous planning of generation system and transmission network, with GenCo, TransCo, Existing Network and New Load as players, it can be shown that player with high capacity will have opportunity to enter coalition eralier than the other players.

(d) Negotiation process in this game mechanism can be accomplished by adjusting characteristic function value that is given in the early process of coalition.

\section{Acknowledgment}

The authors gratefully acknowledge the contributions of Henny Ika Septyani, Totoh A and Sudarmono for their works on computation and programming in MatLab.

\section{References}

[1] Pereira, M. V. F., Pinto, L. M. V., Cunha, S. H. F. and Oliveira, G. C. (1985) Decomposition Approach to Automated Generation/Transmission Expansion Planning. IEEE Transactions on Power Apparatus and Systems, Vol. PAS-104.N0.11,1985,30743083.

[2] Li, W. and Billinton, R. (1993). A Minimum Cost Assessment Method for Composite Generation and Transmission System Expansion Planning. IEEE Transaction on Power System, Vol. 8, No. 2, 628-635

[3] Chi Keung Woo, Ira Horowitz, Jennifer Martin, Reliability Differentiation of Electricity Transmission, Journal of Regulatory Economics :13:277-292, Kluwer Academic Publishers, 1998

[4] Botterud, A., IIic, M.D. and Wangesteen, I. (2005). Optimal Investments in Power Generation under Centralized and Decentralized Decision Making. IEEE Transaction on Power System, Vol 20, Issue 1, 254-263

[5] Borenstein, S., Bushnell, J. and Stoft, S. (2000). The Competitive Effects of Transmission Capacity in a Deregulated Electricity Industry. RAND Journal of Economics, Vol.31, No.2,294-325

[6] Ziad Yuones, Marija Ilic, Generation Strategies for Gaming Transmission Constraints, Will the Deregulated Electric Power Market Be an Oligopoly?, IEEE Power System, 1998

[7] Lina P Graces, Antonio J Conejo, Raquel Garcia Bertrand, Ruben Romero, A Bilevel Approach to Transmission Expansion Planning Within a Market Environtment, will be accepted in IEEE Transaction on Power System, 2009

[8] Mohammad Sadegh Sepasian, Hossein Seifi, Asghar Akbari Foroud, Alireza Hatami, A Multiyear Security Constrained Hybrid Generation-Transmission Expansion Planning Algorithm Including Fuel Supply Cost, will be accepted in IEEE Transaction on Power System, 2009

[9] Jun Hua Zhao, Zhao Yang Dong, Peter Lindsay, Kit Po Wong, Flexible Transmission Expansion Planning With Uncertainties in an Electricity Market, IEEE Transaction on Power System Vol.24, No.1, February 2009

[10] Matteo Tesser, Adela Pages, Narcis Nabona, An Oligopoly Model for Medium Term Power Planning an a Liberalized Electricity Market, IEEE Transaction on Power System Vol.24, No.1, February 2009 
[11] Vishnu Nanduri, Tapas K Das, Patricio Rocha, Generation Capacity Expansion in Energy Markets Using a Two Level Game Theoritic Model, will be accepted in IEEE Transaction on Power System, 2009

[12] Jianhui Wang, Mohammad Shahihdehpour, Zuyi Li, Audun Botterund, Strategic Generation Capacity Expansion Planning With Incomplete Information, IEEE Transaction on Power System Vol.24, No.2, May 2009

[13] Jae Hyung Roh, Mohammad Shahidehpour, Lei Wu, Market Based Generation Transmission Planning with Uncertainties, IEEE Transaction on Power System Vol.24, No.3, August 2009

[14]P A J Fonseka, T K Saha, ZY Dong, A Price Based Approach to Generation Investment Planning in Electricity Markets, IEEE Transaction on Power System Vol.23, No.4, November 2008

[15] Muhammad Nurdin, Nanang Hariyanto, Henny Ika Septyani, Transmission cost and energy lost cost allocation of electric power system using cooperative game theory, EECIS 2006, Malang

[16] Nanang Hariyanto, Muhammad Nurdin, Deny H, Isnuwardianto Identfying Overload Condition using Cascading Index and Fuzzy System, IPEC 3 - December 2007, Singapura or IEEE Catalog Number 07EX1686C, ISBN : 978-981-05-9423-7

[17] Sebastian de la Torre, Antonio J Conejo, Javier Contreras, Transmission Expansion Planning in Electricity Market, IEEE Transaction on Power System Vol.23, No.1, February 2008

[18] Osman Bulent Tor, Ali Nezih Guven, Mohammad Shahidehpour, Congestion Driven Transmission Planning Considering the Impact of Generator Expansion, IEEE Transaction on Power System Vol.23, No.2, May 2008

[19]Scott R Dehman, Donald J Morrow, Jamed D Weber, Advanced Sensitivity Analysis for Long Range Transmission Expansion Planning, Proceeding of the 41st Hawaii International Conference on System Science, 2008

[20] Changhui Ma, Jun Liang, Xinsheng Niu, Hengxu Zhang, Pengfei Zhang, On transmission Expansion Planning Considering Security Risk in Competitive Electricity Markets, DRPT 2008, 6-9 April 2008, Nanjing China.

[21] Simon KK Ng, C W Lee, J Zhong, A Game Theoritic Approach to Study Strategic Interaction Between Transmission and Generation Expansion Planning, IEEE Transaction on Power System, 2006

[22]Wene Lu, Ettore Bompard, Roberto Napoli, Xiuchen Jiang, Heuristic Procedures for Transmission Planning in Competitive Electricity Markets, Electric Power System Research 77, 2007, 1337-1348, Science Direct, Elsevier, 2007

[23] Enzo E Sauma, Shmuel S Oren, Economic Criteria for Planning Transmission Investment in Restructured Electricity Markets, IEEE Transaction on Power System, Vol 22, No.4, November 2007

[24] Jose L Ceciliano Meza, Mehmet Bayram Yildirim, Abu S M Masud, A Model for the Multiperiod Multiobjective Power Generation Expansion Problem, IEEE Transaction on Power System, Vol 22, No.2, May 2007

[25] Jae Hyung Roh, Mohammad Shahidehpour, Yong Fu, Market Based Coordination of Transmission and Generation Capacity Planning, IEEE Transaction on Power System, Vol 22, No.2, May 2007

[26] Rosa Serrano, Hugh Rudnick, Juan C Araneda, Privat planning of transmission expansion through cooperative games, IEEE Power Tech 2007 


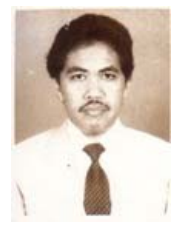

Nanang Hariyanto was born in Jember, Jawa Timur INDONESIA, on July 26, 1962. He graduated from the Electrical Engineering Department, Bandung Institute of Technology. His employment experience included Synatech Industry, and as a researcher at Power System Laboratory, ITB INDONESIA. His special fields of interest included power system planning and dynamic stability.

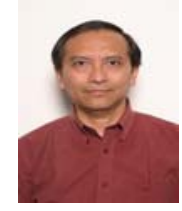

Muhammad Nurdin was born in Wonogiri, Jawa Tengah, INDONESIA, on February 22,1954. He graduated his Doctoral Program from the INPT Grenoble at 1988, France. His employment as a chairman of Power Engineering Program, School of Electrical Engineering ITB INDONESIA., with Power System Laboratory ITB, and with Indonesian National Commitee for Electric Power Reliability. $\mathrm{He}$ is a member of IEEE, with Power Engineering Society. His special fields of interest included power system operation and dynamic stability.

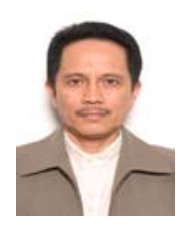

Yanuarsyah Haroen was born in Muaradua, INDONESIA, on June 1,1952. He graduated his Doctoral Program from the INPT Toulouse, France. He is a Professor in School of Electrical Engineering ITB INDONESIA, with Electric Conversion Laboratory ITB. He is a Senior Member of IEEE. His special fields of interest included power electronic and dynamic of electric machinery.

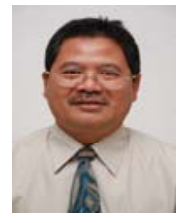

Carmadi Machbub was born in Kuningan, Jawa Barat INDONESIA, on January 18,1954. He graduated his Doctoral Program from the Univ de Nantes, France. He is a Professor in School of Electrical Engineering ITB INDONESIA, with Control and Intelegent System Research Group ITB. His special fields of interest included automatic control and intelegent system. 